\title{
NOVEL PSO STRATEgY For Transmission CONGESTION MANAGEMENT
}

\author{
Hemant Mahala ${ }^{1}$ and Yogendra Kumar ${ }^{2}$ \\ ${ }^{1}$ Department of Electrical Engineering, Dr. K.N.Modi University, Newai \\ ${ }^{2}$ Department of Electrical Engineering, MANIT, Bhopal
}

\begin{abstract}
In post deregulated era of power system load characteristics become more erratic. Unplanned transactions of electrical power through transmission lines of particular path may occur due to low cost offered by generating companies. As a consequence those lines driven close to their operating limits and becomes congested as the lines are originally designed for traditional vertically integrated structure of power system. This congestion in transmission lines is unpredictable with deterministic load flow strategy. Rescheduling active and reactive power output of generators is the promising way to manage congestion. In this paper Particle Swarm Optimization (PSO) with varying inertia weight strategy, with two variants e1-PSO and e-2 PSO is applied for optimal solution of active and reactive power rescheduling for managing congestion. The generators sensitivity technique is opted for identifying participating generators for managing congestion. Proposed algorithm is tested on IEEE 30 bus system. Comparison is made between results obtained from proposed techniques to that of results reported in previous literature.
\end{abstract}

\section{KEYWORDS}

Electricity Market, Generator sensitivities, Particle Swarm Optimization, Rescheduling, Transmission Congestion.

\section{INTRODUCTION}

The problem of transmission congestion is predominating in deregulated electricity market structure as the existing lines are originally designed for vertically integrated unbundled operation. A transmission line is said to be congested when it operates closure to its operating limits. Under competitive environment large units of Generating Companies may offer lower electricity price to customers for profit maximization, this may change the power flow pattern and the transmission lines are often driven close to their thermal limits in order to satisfy the increased electric power consumption and trades due to increase of the unplanned power exchanges. If the exchanges were not controlled, some lines located on particular paths may become congested. To relieve the line from congestion and to ensure the secure operation of power system in a complex electricity market, appropriate congestion management strategy necessitates to be implemented. Congestion can be reduced by generation re-dispatch, load redispatch, reactive power support, and transmission system expansion. In [1] PSO is used to solve multi-objective problem formulation for $\mathrm{CM}$, where generator rescheduling is formulated as an optimization problem with the objective of obtaining minimum rescheduling cost and proposed objective of achieving minimum real power loss. A vector evaluated particle swarm optimization is applied to solve CM optimization problem in electricity market [2]. PSO is implemented to determine optimal sizing of static var Compensators (SVCs) for minimization of transmission losses considering cost function [3]. In objective function installation of SVC cam be calculated using the cost function. The result obtained with PSO is compared with Bee Algorithm (BA).

In [4] a comprehensive coverage of different PSO applications in solving optimization problems in the area of electric power systems is presented. It highlights the PSO key features and advantages over other various optimization algorithms. Furthermore, recent trends with regard to 
PSO development in this area are explored.PSO algorithm for the solution of nonlinear optimization problem of CM is implemented in [5]. The problem formulation involves objective function which minimizes the total cost incurred for adjusting real power generation of the participating generators and the various constraints represents final powers as a function of market clearing values. upper and lower limits for real and reactive power of generators, upper and lower bound for real power adjustment of the participating generators, incremental and detrimental change in real power of generator line loading limit, lower and upper bound for load bus voltages. In this paper a novel PSO is implemented for optimal rescheduling of active and reactive power output of generators. In addition to its classical version PSO with varying inertia weight strategy is implemented on IEEE 30 bus test system.

\section{Problem Formulation}

To manage congestion within the constrictions, problem formulation must be carefully done by considering all probable factors that affects the system. In the proposed strategy of congestion management, rescheduling of generator outputs is considered. The problem of optimum rescheduling of generator outputs is formulated including objective function and constraints.

\subsection{Objective function}

Objective of the work is to relieve the line from congestion and minimize the rescheduling cost of generators participating in managing congestion. The active and reactive power rescheduling costs of generators for congestion management based on the bids received is given by-

Minimize $\sum_{\mathrm{g}}^{\mathrm{Ng}} \mathrm{C}_{\mathrm{Pg}}\left(\Delta \mathrm{P}_{\mathrm{g}}\right) \Delta \mathrm{P}_{\mathrm{g}}+\sum_{\mathrm{g}}^{\mathrm{Ng}} \mathrm{C}_{\mathrm{Qg}}\left(\Delta \mathrm{Q}_{\mathrm{g}}\right) \Delta \mathrm{Q}_{\mathrm{g}}$

Where:

$\mathrm{C}_{\mathrm{Pg}}$ : Cost of the active power rescheduling corresponding to the incremental/ decremental price bids submitted by generator-g participating in congestion management.

$\Delta \mathrm{P}_{\mathrm{g}}$ : Active power adjustment of the generator-g.

$\Delta \mathrm{Q}_{\mathrm{g}}$ : Reactive power adjustment of the generator-g.

$\mathrm{C}_{\mathrm{Qg}}\left(\Delta \mathrm{Q}_{\mathrm{g}}\right)$ : Cost of the reactive power rescheduling of generator-g participating in congestion management. It is expressed as:

$\mathrm{C}_{\mathrm{Qg}}\left(\Delta \mathrm{Q}_{\mathrm{g}}\right)=\left\{\mathrm{C}_{\mathrm{g}}^{\mathrm{P}}\left(\mathrm{S}_{\mathrm{Gmax}}\right)-\mathrm{C}_{\mathrm{g}}^{\mathrm{g}}\left(\sqrt{\mathrm{S}_{\mathrm{Gmax}}^{2}-\Delta \mathrm{Q}_{\mathrm{g}}^{2}}\right)\right\} \times \varphi$

Where, $C_{g}^{P}$ is the cost of active power generation of generator $g$ and is expressed as a quadratic function as

$\mathrm{C}_{\mathrm{g}}^{\mathrm{P}}\left(\Delta \mathrm{PG}_{\mathrm{gn}}\right)=\mathrm{a}_{\mathrm{n}}\left(\Delta \mathrm{PG}_{\mathrm{gn}}^{2}\right)+\mathrm{b}_{\mathrm{n}}\left(\Delta \mathrm{PG}_{\mathrm{gn}}\right)+\mathrm{c}_{\mathrm{n}}$

\subsection{Constraints}

To ensure the operation of system within operating range with feasible solutions inequality and equality constraints are incorporated. In the present work constraints are power flow constraint (4), operating limit constraints (5) (6)

Subject to

$\left(\sum_{\mathrm{g}}^{\mathrm{Ng}}\left(\left(\mathrm{GS}_{\mathrm{pg}}\right) \Delta \mathrm{P}_{\mathrm{g}}\right)+\mathrm{P}_{\mathrm{ij}}^{\mathrm{o}}\right)^{2}+\left(\sum_{\mathrm{g}}^{\mathrm{Ng}}\left(\left(\mathrm{GS}_{\mathrm{qg}}\right) \Delta \mathrm{P}_{\mathrm{g}}\right)+\mathrm{Q}_{\mathrm{ij}}^{\mathrm{o}}\right)^{2} \leq\left(\mathrm{S}_{\mathrm{ij}}^{\max }\right)^{2}$ 


$$
\begin{aligned}
& \mathrm{P}_{\mathrm{g}}-\mathrm{P}_{\mathrm{g}}^{\min }=\Delta \mathrm{P}_{\mathrm{g}}^{\min } \leq \Delta \mathrm{P}_{\mathrm{g}} \leq \Delta \mathrm{P}_{\mathrm{g}}^{\max }=\mathrm{P}_{\mathrm{g}}^{\max }-\mathrm{P}_{\mathrm{g}} \\
& \mathrm{Q}_{\mathrm{g}}-\mathrm{Q}_{\mathrm{g}}^{\text {min }}=\Delta \mathrm{Q}_{\mathrm{g}}^{\text {min }} \leq \Delta \mathrm{Q}_{\mathrm{g}} \leq \Delta \mathrm{Q}_{\mathrm{g}}^{\max }=\mathrm{Q}_{\mathrm{g}}^{\max }-\mathrm{Q}_{\mathrm{g}}
\end{aligned}
$$

Where:

$\mathrm{GS}_{\mathrm{pg}}:$ Active power generator sensitivity

$\mathrm{GS}_{\mathrm{qg}}$ : Reactive power generator sensitivity

\section{Particle Swarm Optimization}

Particle swarm optimization is a meta- heuristic optimization technique first introduced by Kennedy and Eberhart in 1995[6].The original version of PSO can only deals with nonlinear continuous optimization problems. With further advancement in the algorithm PSO can be implemented to complex problems of engineering and sciences to calculate global optimal solution. It is an efficient addition to the class of population based search techniques. PSO algorithm is on the whole inspired by social behaviour of organisms like shoaling of fish, the swarming of insects. In its colonial form, PSO initializes with random particle generation and velocity vector is used to update the particles. The best position visited during its flying tour in the problem search space referred to as personal best position (p-best), The best position visited by all the particle is memorized, i.e., the best position among all p-best positions referred as global best position (gbest), Objective function is evaluated every solution produced in an iteration. This process continues until final criterion is achieved which either can be assigned as desired solution or number of iterations.

Let an $\mathrm{n}$ dimensional search space with $\mathrm{N}$ no. of particles, at an instant $\mathrm{t}$ particle $\mathrm{i}$ have its position defined by $X_{t}^{i}$ and velocity by $V_{t}^{i}$. Velocity and position of each particle in the next generation can be calculated as-

$\mathrm{V}_{\mathrm{t}+1}^{\mathrm{i}}=\mathrm{w} \times \mathrm{V}_{\mathrm{t}}^{\mathrm{i}}+\mathrm{c} 1 \times \operatorname{rand}() \times\left(\mathrm{P}_{\mathrm{t}}^{\mathrm{i}}-\mathrm{X}_{\mathrm{t}}^{\mathrm{i}}\right)+\mathrm{c} 2 \times \operatorname{rand}() \times\left(\mathrm{P}_{\mathrm{t}}^{\mathrm{g}}-\mathrm{X}_{\mathrm{t}}^{\mathrm{i}}\right)$

$\mathrm{X}_{\mathrm{t}+1}^{\mathrm{i}}=\mathrm{X}_{\mathrm{t}}^{\mathrm{i}}+\mathrm{V}_{\mathrm{t}+1,}^{\mathrm{i}}, \forall \mathrm{i}=1,2 \ldots . \mathrm{N}$

Where $\mathrm{N}$ is number of particles in the swarm, $\mathrm{w}$ is Inertia weight, $\mathrm{c} 1 \& \mathrm{c} 2$ are acceleration constants, rand () is uniform random value between 0 to $1, \mathrm{P}_{\mathrm{t}}^{\mathrm{g}}$ is global best at generation $t, \mathrm{P}_{\mathrm{t}}^{\mathrm{i}}$ is best position that particle i could find so far. The first part of equation (8) represents the inertia of previous velocity, second part is cognition part and tells about the personal information of particle and third part is social component as it represents information among particles.

\section{PSO With Natural EXPONEnt Inertia Weight Strategy}

Inertia weight in PSO plays vital role in exploring the solutions. It determines the contribution of rate of velocity obtained in previous step to the present. In basic PSO of Eberhart and Kennedy there was no inertia weight. First time Shi and Eberhart [7] introduced the concept of constant inertia weight. Further the concepts of varying inertia weight strategies were presented in [8]. In this paper improved PSO with two natural exponent strategies e1-PSO and e-2 PSO is used to get better results as compared to standard PSO. The variation of inertia weight with each iteration, for e1-PSO and e-2 PSO is as follows.

$$
\begin{aligned}
& w(t)=w_{\text {min }}+\left(w_{\text {max }}-w_{\text {min }}\right) \cdot e^{\frac{\text { iter }}{\left(i_{\text {termax } / 10}\right)}} \\
& w(t)=w_{\text {min }}+\left(w_{\text {max }}-w_{\text {min }}\right) \cdot e^{-\left[\frac{\text { iter }}{\left(\text { iter }^{\text {max } / 4)}\right]^{2}}\right.}
\end{aligned}
$$




\section{Case Study}

Simulation studies were carried out on Intel Core 2 Duo processor, 2GB of RAM, $2.20 \mathrm{GHZ}$ system in MATLAB 7.6 platform. The algorithm has been tested on IEEE 30 bus system [9]. IEEE 30 bus system consists of 6 generators, 24 load buses and 41 branches. Generator at slack bus is numbered as 1 , while remaining are taken as 2,3,4,5 and 6. Numbering of load buses is taken from 7 to 30 . Generating unit characteristics are given in table 1. Details of congested line and generator sensitivity values corresponding to the congested line are given in table 2 and 3.Line between bus 1 and 7 are congested, the rated MVA is 130 and actual flow is 138MVA. Generator data is given in table 1 . Generator active and raective power sensitivities are given in table 2 .

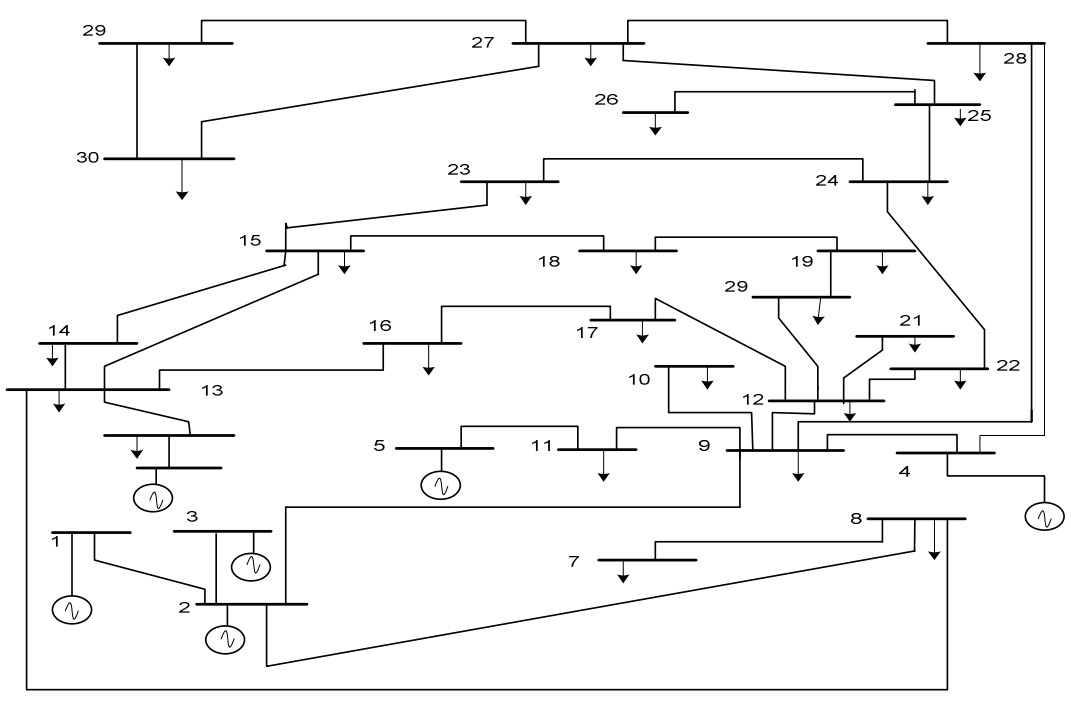

Figure1. Modified IEEE 30 bus system

Table 1: Generating unit characteristic of IEEE 30 bus system.

\begin{tabular}{|c|c|c|c|c|c|}
\hline Unit & \multicolumn{3}{|c|}{ Cost Coefficients } & \multicolumn{2}{c|}{ Generator Limits } \\
\hline & $\begin{array}{c}\mathrm{a} \\
\left(\$ \mathrm{MW}^{2} \mathrm{~h}\right)\end{array}$ & $\begin{array}{c}\mathrm{b} \\
(\$ / \mathrm{MWh})\end{array}$ & $\begin{array}{c}\mathrm{c} \\
(\$ \mathrm{~h})\end{array}$ & $\begin{array}{c}\text { Pgmin } \\
(\mathrm{MW})\end{array}$ & $\begin{array}{c}\text { Pgmax } \\
(\mathrm{MW})\end{array}$ \\
\hline 1 & 0.00375 & 2 & 0 & 50 & 250 \\
\hline 2 & 0.0175 & 1.75 & 0 & 20 & 80 \\
\hline 3 & 0.0625 & 1 & 0 & 15 & 50 \\
\hline 4 & 0.00834 & 3.25 & 0 & 10 & 35 \\
\hline 5 & 0.025 & 3 & 0 & 10 & 30 \\
\hline 6 & 0.025 & 3 & 0 & 12 & 40 \\
\hline
\end{tabular}


Electrical and Electronics Engineering: An International Journal (ELELIJ) Vol 5, No 2, May 2016

Table 2. Generator sensitivities

\begin{tabular}{|c|c|c|c|c|c|c|}
\hline \multicolumn{1}{|c|}{ Unit } & 1 & 2 & 3 & 4 & 5 & 6 \\
\hline GS Pg & 0.00 & -0.85 & -0.78 & -0.68 & -0.66 & - \\
& & & & & & 0.64 \\
\hline GS Qg & -0.77 & -0.86 & -0.74 & -0.78 & -0.76 & - \\
& & & & & & 0.77 \\
\hline
\end{tabular}

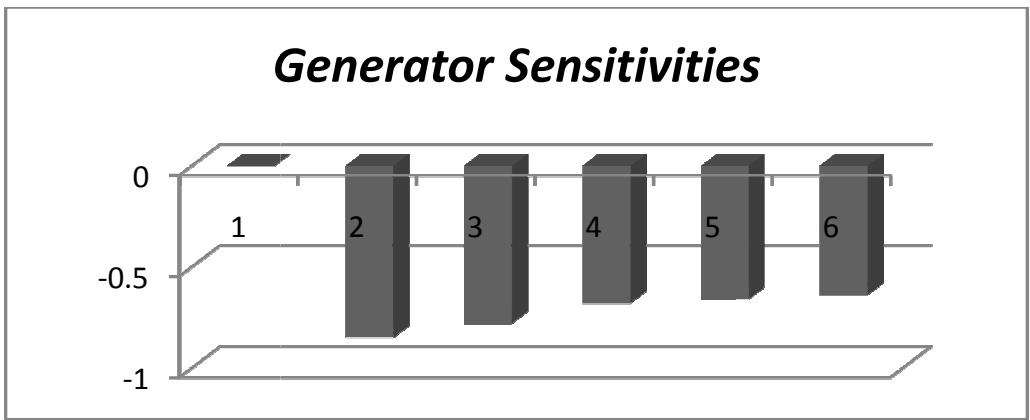

Figure 2. Plot of active power generator sensitivities of IEEE 30 bus system

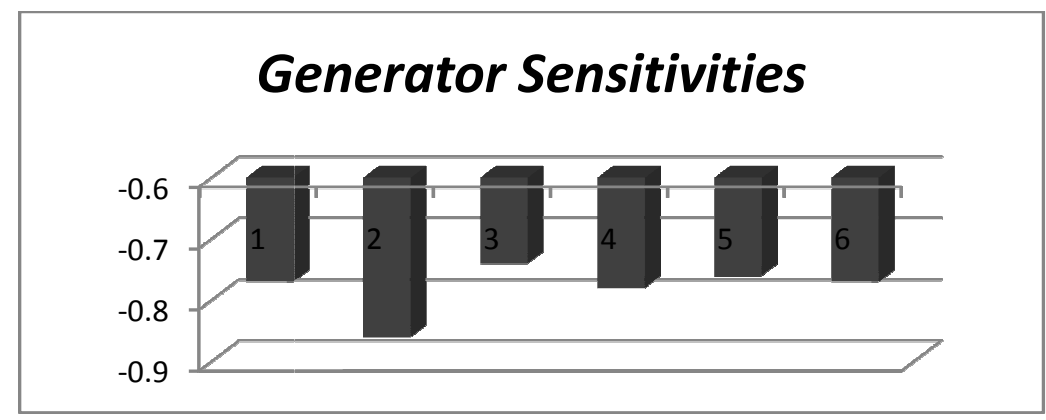

Figure 3. Plot of reactive power generator sensitivities of IEEE 30 bus system

\section{PSO Algorithm For VARYing Inertia Weight Strategy}

Step 1: Select PSO parameters - acceleration coefficients $\mathrm{c} 1 \& \mathrm{c} 2$, inertia weight w, population size

Step 2: Initialize particles with their position and velocity

Step 3: Initialize $\mathrm{p}_{\text {best }}$ and $\mathrm{g}_{\text {best }}$

Step 4: Set iteration count $=0$

Step 5: Calculate position matrix $X_{t}^{i}$

Step 6: Evaluate objective function

Step 7: Is objective value is greater than $p_{\text {best }}$ ?

If yes, set it as new $p_{\text {best }} \&$ go to next step.

Else go to next step

Step 8: Is fitness value is greater than $\mathrm{g}_{\text {best }}$ ?

If yes, set it as new $\mathrm{g}_{\text {best }} \&$ go to next step.

Else go to next step

Step 9: Update Position of Particles by Using Equation (8) 
Electrical and Electronics Engineering: An International Journal (ELELIJ) Vol 5, No 2, May 2016

Step10: Check whether stopping criteria (maximum number of iterations) reached?

If yes then got to step 14

Else go to next step.

Step11: Calculate inertia weights by using equation (9) \& eq. (10).

Step12: Update velocity of particles using eq. (7).

Step13: Update position of particles using eq. (8).

Step14: Check for stopping criteria

If iterations $<\max$. no. of iteration then increase iteration count by $1 \&$ go to step 5 .

Else go to step 14.

Step15: Final $g_{\text {best }}$ position of particles is optimal solution.

\section{RESUlt AND COMPARISONS}

Table 4: Comparisons of results on IEEE 30 bus system

\begin{tabular}{|c|c|c|c|c|c|}
\hline & & $\begin{array}{l}\text { Result Reported } \\
\text { in [10 ] }\end{array}$ & PSO & e1 -PSO & e2 -PSO \\
\hline \multirow{6}{*}{$\begin{array}{c}\text { Active } \\
\text { Power } \\
\text { Rescheduling } \\
\text { (MW) }\end{array}$} & $\Delta \mathrm{Pg} 1$ & -50.09 & 42.4795 & 54.8940 & 3.6139 \\
\hline & $\Delta \mathrm{Pg} 2$ & Not participated & 37.6121 & 1.8665 & 36.7628 \\
\hline & $\Delta \mathrm{Pg} 3$ & 17.00 & -4.0184 & 12.9445 & 15.3151 \\
\hline & $\Delta \mathrm{Pg} 4$ & 24.43 & 7.5377 & 2.7328 & 10.2114 \\
\hline & $\Delta \mathrm{Pg} 5$ & Not participated & -10.9927 & -15.2149 & -5.9628 \\
\hline & $\Delta \mathrm{Pg} 6$ & 6.08 & -3.6867 & 6.2443 & -3.6899 \\
\hline \multicolumn{2}{|c|}{$\begin{array}{l}\text { Total Active Power } \\
\text { Rescheduling } \\
\text { (MW) }\end{array}$} & 96.60 & 68.9315 & 63.4672 & 56.2505 \\
\hline \multicolumn{2}{|c|}{$\begin{array}{c}\text { Total active power } \\
\text { rescheduling Cost }(\$ / \mathrm{h})\end{array}$} & 28901 & 23117 & 19450 & 18609 \\
\hline \multirow{6}{*}{$\begin{array}{c}\text { Reactive } \\
\text { Power } \\
\text { Rescheduling } \\
\text { (MVAR) }\end{array}$} & $\Delta \mathrm{Qg} 1$ & -35 & 34.9709 & 6.1094 & 28.6309 \\
\hline & $\Delta \mathrm{Qg} 2$ & Not participated & 50.3687 & 5.4376 & 32.9824 \\
\hline & $\Delta \mathrm{Qg} 3$ & 58.20 & 27.652 & 37.6894 & -9.6063 \\
\hline & $\Delta \mathrm{Qg} 4$ & 27.29 & 0.98 & 35.2871 & 17.4261 \\
\hline & $\Delta$ Qg5 & Not participated & 13.8934 & -0.9634 & 8.1270 \\
\hline & $\Delta$ Qg6 & -39.31 & 3.2213 & 11.6435 & 11.8535 \\
\hline \multicolumn{2}{|c|}{$\begin{array}{l}\text { Total Reactive Power } \\
\text { Rescheduling } \\
\text { (MVAR) }\end{array}$} & 159.80 & 131.0863 & 95.2036 & 89.4136 \\
\hline
\end{tabular}


Electrical and Electronics Engineering: An International Journal (ELELIJ) Vol 5, No 2, May 2016

\begin{tabular}{|c|c|c|c|c|}
\hline $\begin{array}{c}\text { Total reactive power } \\
\text { rescheduling Cost }(\$ / \mathrm{h})\end{array}$ & 7048 & 5342 & 4352 & 4075 \\
\hline Time $(\mathrm{Sec})$ & Not Reported & 0.40640 & 0.39785 & 0.39812 \\
\hline
\end{tabular}

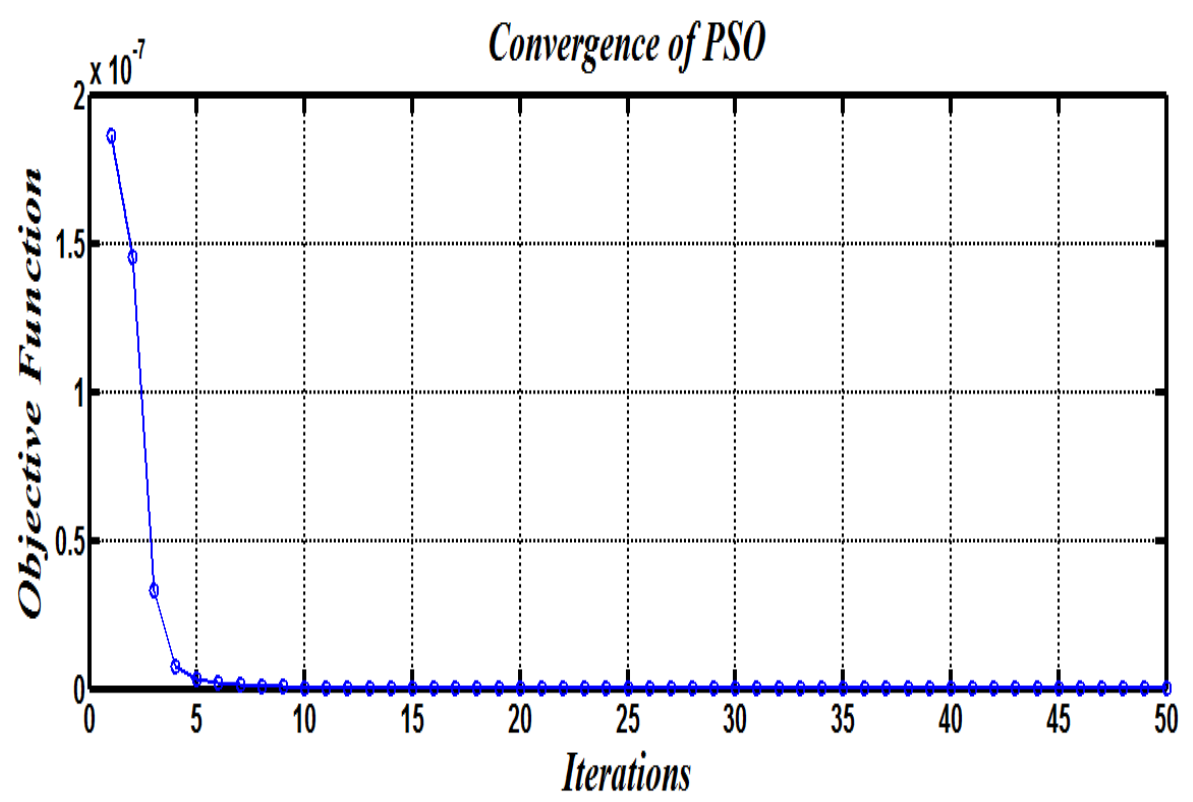

Figure 4.Convergence characteristic of PSO (IEEE 30 Bus system)

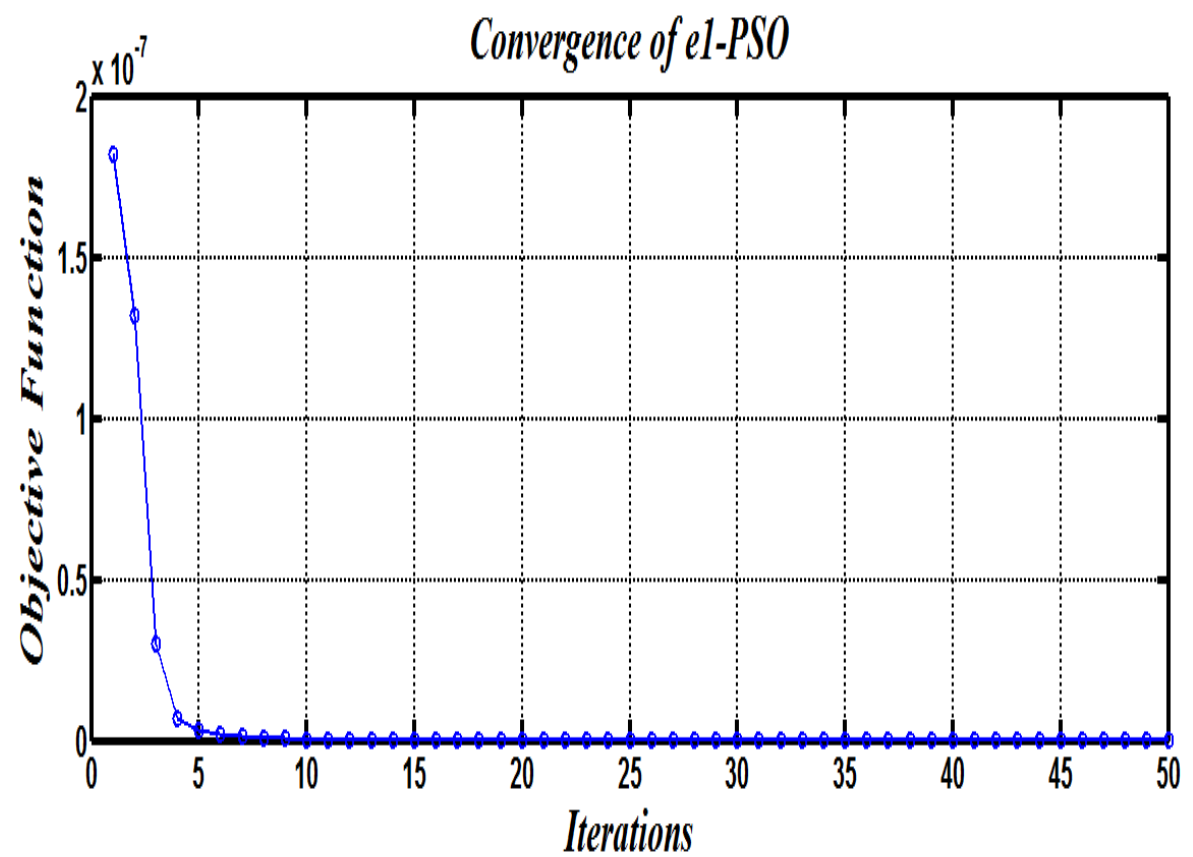




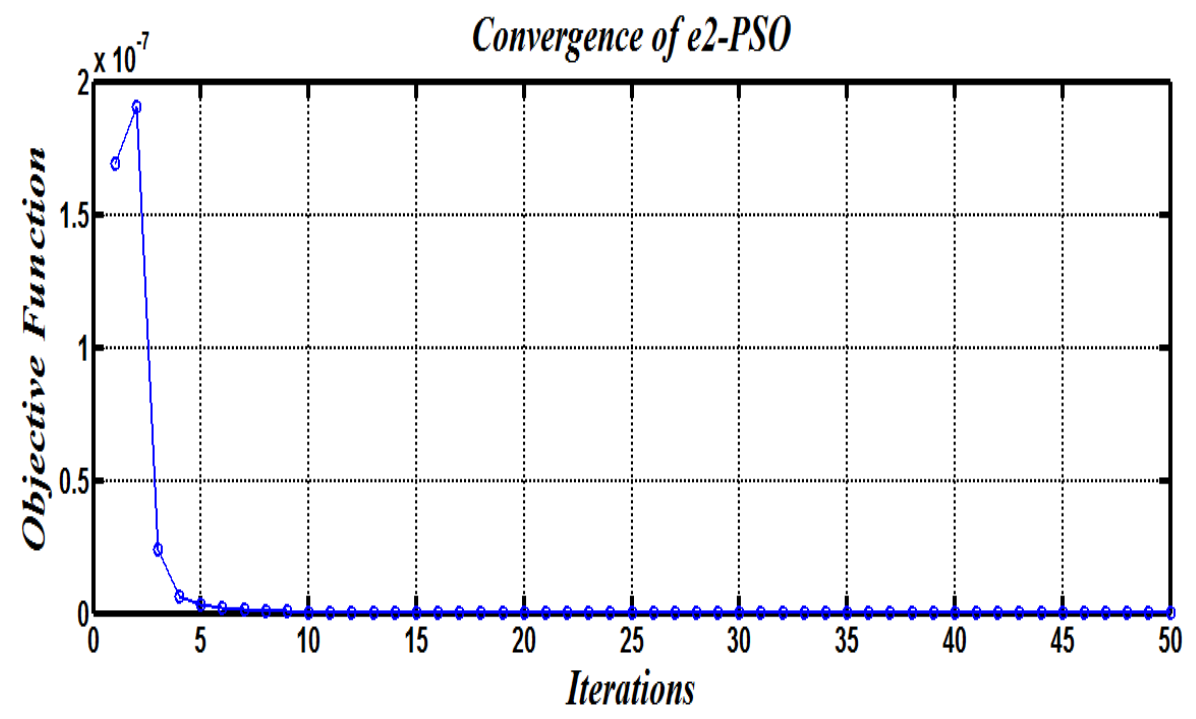

Figure 6.Convergence characteristic of e1-PSO (IEEE 30 Bus system)

\section{CONCLuSion \& Future SCOPE}

In this paper optimal active and reactive power rescheduling output of generators are calculated for transmission congestion management to ensure the reliability of the deregulated power system under consideration. The results obtained by original PSO, e1-PSO and e2-PSO are compared for better convergence. Results show that modified PSO with varying inertia weight in successive iterations exhibits better results. Techniques are implemented on IEEE 30 bus system. All generators are selected for congestion management due to few numbers. The proposed technique can be further improved by considering technical factors like transmission losses. Better convergence of results can be obtained by hybrid PSO techniques.

\section{REFERENCES}

[1] S. Charls Raja, P. Venkatesh \& B.V. Manikandan (2011), "Transmission congestion management in restructured power systems", Proceedings of ICETECT, pp23-28.

[2] O. Abedinia, N. Amjady, H.A. Shayanfar \& A. Ghasemi (2012), "Optimal congest management based VEPSO on electricity market", International Journal on "Technical and Physical Problems of Engineering" Vol. 4, No. 2, pp 56-62.

[3] Siti Amely Jumaat, Ismail Musirin \& Muhammad Murtadha Othman (2011), "Transmission loss minimization using SVC based on particle swarm optimization", IEEE symposium on industrial electronics and applications, Sept. 25-28, Langkawi, Malasiya.

[4] M. R. AlRashidi \& M. E. El-Hawary (2009), "A Survey of Particle Swarm Optimization Applications in Electric Power Systems" IEEE Transactions on Evolutionary Computation, Vol. 13, No. 4.

[5] Sujatha Balaraman, N.kamaraj (2010), "Application of differential evolution for congestion management in power system", Modern Applied Science, Vol. 4, No. 8.

[6] Kennedy J. \& Eberhart R (1995), "Particle swarm optimization", in Proc. of the IEEE international conference on Neural networks, pp.1942-1948.

[7] Y. Shi, R.C. Eberhart, "Empirical study of particle swarm optimization", In Proceeding of the Congress on Evolutionary Computation, Vol. 3, pp. 1945_1950, 1999.

[8] J. C. Bansal, P. K. Singh,Mukesh Saraswat, Abhishek Verma, Shimpi Singh Jadon, ,Ajith Abraham (2011), "Inertia Weight Strategies in Particle Swarm Optimization" 2011 Third World Congress on Nature and Biologically Inspired Computing. 2011, pp 640-647. 
Electrical and Electronics Engineering: An International Journal (ELELIJ) Vol 5, No 2, May 2016

[9] S. Charles Raja, P. Venkatesh, B.V. Manikandan (2011), "Transmission congestion management in restructured power systems", Proceedings of ICETECT, 2011.

[10] FarzadVazinram, MajidGandomkar,Mehdi BayatMokhtari (2014), "Congestion Management Using Real and Reactive Power Rescheduling Based on Big Bang-Big Crunch Optimization Algorithm" International Journal of Automation and Power Engineering, Vol. 3, Issue 3.

\section{Authors}

Hemant Mahala is Associate Professor in department of Electrical \& Electronics Engineering, O.I.S.T., Bhopal. He did his Bachelor of Engineering from L.N.C.T., Bhopal, M.Tech from M.A.N.I.T., Bhopal and is currently pursuing Ph.D. from D.K.N.M.U., Newai (Raj.). He is life member of ISTE, IACSIT, IAENG and several other technical societies

Yogendra Kumar is Professor of Electrical \& Electronics Engineering Department, M.A.N.I.T., Bhopal. He did his Bachelor of Engineering from, Jamia Millia Islamia, New Delhi, M.Tech. from Barkatulla University and $\mathrm{PhD}$ in power system from IIT Roorkee. He has published number of papers in national and international journals and conferences.
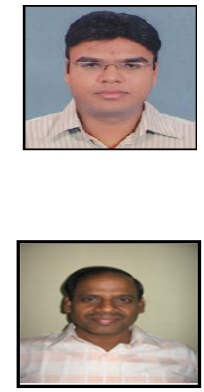